\title{
The formation of research skills of the master's degree students of choreographic art field of study within the framework of the study of "philosophy of dance" program
}

\author{
Journal for Educators, Teachers and Trainers, Vol. 12 (1) \\ https://jett.labosfor.com/
}

Date of reception: 18 April 2020

Date of revision: 16 July 2020

Date of acceptance: 15 September 2020

Tatiana Vasilievna Portnova (2021). The formation of research skills of the master's degree students of choreographic art field of study within the framework of the study of "philosophy of dance" program. Journal for Educators, Teachers and Trainers, Vol. 12(1). 61 - 66.

${ }^{1}$ Doctor of Arts, Professor, Moscow State University named after A. N. Kosygin (Moscow), 


\title{
Journal for Educators, Teachers and Trainers, Vol. 12 (1) \\ ISSN 1989 - 9572 \\ https://jett.labosfor.com/
}

\section{The formation of research skills of the master's degree students of choreographic art field of study within the framework of the study of "philosophy of dance" program}

\section{Tatiana Vasilievna Portnova ${ }^{1}$}

${ }^{1}$ Doctor of Arts, Professor, Moscow State University named after A. N. Kosygin (Moscow),

Email ID: infotatiana-p@mail.ru

\begin{abstract}
The objective of the article is the systematic presentation of philosophical approaches to the understanding of dance through the course "Philosophy of Dance", studied at the master's degree level in the "Choreographic Art" field of study. The mastering of theoretical and practical skills of sensemaking by means of choreographic art in the system of individual and social self-knowledge have been considered. Studying dance from the philosophical point of view, gives an opportunity to see many facts in its type structure and the history of development in general. Of particular importance is the expansion and deepening of the world outlook and research interest of master's students to modern historical, philosophical and aesthetic assessments of various aspects that take place in the art of dance, the analytical consideration of the range of philosophical interpretations of choreographic works and their inclusion in the independent process of reflection on stage practice. With the help of competence characteristics, the importance of forming the skills of philosophical analysis of choreographic works, their evaluation using anthropological, ethical and aesthetic criteria have been shown. Mastering the culture of thinking, the ability to perceive, analyze and generalize the aesthetic image in the context of studying the philosophical paradigm of dance contribute to the formation of research interest in it.
\end{abstract}

Keywords: philosophy of dance, research interest, aspects of study, choreographic art

\section{INTRODUCTION}

Relevance of the article is determined by: multidimensional characterization of the problem, identification of the main aspects in the study of the "Philosophy of Dance" program for the level of master's degree, as well as the lack of special works on the issues raised in this study. The "Philosophy of Dance" course is included in the choreography and staging profile of the professional cycle of master's training in the "Choreographic Art" field of study. This discipline aims to deepen and expand the world outlook and research interest of students to modern historical and philosophical assessments of various aspects of dance art, to focus on the applied content of abstraction and synthesis methods on examples of history and theory of choreographic art. Besides, the dance can be called a unique phenomenon of human culture, it is a part of not only professional but also human communication. After all, works of choreography, as well as any other art are addressed to people to whom the author conveys his ideas, notions, experiences and must shed light on their correct understanding. That is why it is important to ensure the mastering of practical skills of sensemaking by means of choreographic art in the flow of individual and social self-knowledge. Parallel courses, which complement the "Philosophy of Dance" discipline, are: "Methodology of Scientific Research in Choreography", "Modern Problems of Science and Art", "Analysis of Choreographic Works". It is necessary for the study of all subsequent disciplines as it forms a holistic view of the subject, problems, methods and concepts related to the field of history, dance theory and practice. The aim of the article is to comprehend the provisions of the own curriculum developed by the author in the direction of master's degree program in choreography, in which it is necessary to develop the specificity 
of the teaching system in the context of a single philosophical space, both in the understanding of the dance itself, and in the choreographic staging and directing thinking.

\section{METHODS OF RESEARCH}

The multifaceted nature of the topic under study required the use of a methodology of theoretical analysis and synthesis capable of revealing the necessary ideas about the philosophical, cultural and disciplinary essence of the art of dance, as well as the use of various research methods:

- integrative, allowing to consider various philosophical aspects of dance as a single complex of linguistic nature of choreography;

- systematization, by means of which the basic principles of philosophical reflection are identified separately and generalized as a whole;

- modeling, on the basis of which it is possible to present the "Philosophy of Dance" program as an important part of choreographic education.

\section{LITERATURE REVIEW}

Philosophical and aesthetic problems in choreography have been considered by researchers (J.Camp, 1996;. D. Davies, 2013; N. Osintseva, 2016; G. Peters, 2016). The theory of analytical description of the author's program is based on the concepts of forming philosophical concepts (M.S. Kagan, 1972, 1996; VI. Uralskaya, 1981), as well as pedagogical and psychological aspects of studying dance (D. Seiffert, 2012) uses the morphological structure of dance, which is included in the philosophical process of scientific cognition in the training of master's degree students (Yu.A. Kondratenko, 2009) reflects on motional directions in choreography in the system of philosophical research (V.V. Kozlov, A.E. Girshon, N.I. Veremeenko, 2006; Malkina - I.G. Pykh, 2005; S.V. Filatov, 1993; A.Ya. Zorn, 2011). At the same time, it forms a system of empirical knowledge of dance philosophy in the genesis of historical sensemaking (K. Blasis, 2008; L.D. Blok, 1987; E.P. Valukin, 1992). An important source of information for the author of the program have been reviews, collections of articles, theoretical and historical works of ballet critics, art critics, in which they touched upon the problems of philosophical approach to choreographic art, evaluated from such an angle the ballet performances on the stage of theaters (A.Ya.Levinson, 2008).

The analysis of both the available single curricula on the philosophy of dance, as well as scientific literature, carried out by the author, revealed the absence of a special study on the study of this issue in the system of master of choreography training, while such a study is important for understanding the modern process of theatrical education.

\section{FINDINGS CONTENT ASPECTS OF THE PROGRAM}

The specificity of the academic discipline consists in a review of the diversity of philosophical and aesthetic programs that consider the art of dance and choreographic theatricality as a kind of substance concerning both structural elements of stage dance, typology of ballet and performing art, and problems of choreographic synthesis. Besides, a modern researcher may be interested in body and corporality in actual dance practices, dance movement therapy as a psychological direction, historical reconstruction and analysis of dance culture of previous centuries, ideas and concepts of the modern theatrical process. "Today the processes that predetermined the appearance of dance philosophy, at the center of which is the problem of language of choreographic imagery, its perception and understanding, provide an opportunity to present, analyze and evaluate this amazing kind of art in the context of contemporary artistic and intellectual life. Only within the framework of the philosophical approach can the question be raised about the essence of choreographic art as well as about the whole range of problems connected with the processes of functioning of choreography, with perception and understanding of the meaning of choreographic works, with comprehension of visual information created by man". [25, p. 3]

Here are a few basic principles about the content, which should be taken into account when teaching this course to show the complex nature of dance. Let's say that the philosophy of dance from the point of view of analysis of professional activity of a ballet dancer is not opposed by the author to his attitude to reality and understanding of the viewer. Only their conjugation allows to understand philosophical thought and real originality as artistic exploration of the world. In addition, the centuries-old history of dance shows that the measure of activity of 
artistic perception of the audience is located in a fairly wide range of philosophical thought and can cover a large group of people with a similar understanding of the idea, in another case, is able to direct the flight of imagination on an individual, only it is inherent in the channel. The aesthetics of perception and developed taste are important here; this aspect is also involved in the thematic structure of the program. [1]

The understanding of dance as a reflection of man (in the human dimension) plays an important role in philosophical comprehension of its nature. One can dwell on the socio-cultural foundations of dance, which lie in the philosophy of art, find the distinctive features of dance art philosophy in comparison with aesthetics, art criticism, musicology, literature, etc. One can characterize the phenomenon of dance in the system of philosophical knowledge and history of philosophy. Also one can present the basic circle of problems and categorical apparatus of philosophy as a science studying dance, as well as consider the prospects for the development of philosophical reflection on dance as an applied field in art philosophy.

Another philosophical direction is related to the type and intraspecific specificity of dance and the integrative notion of its nature. Dance is regarded as one of the most ancient and global art forms for the world culture. The analysis of the arsenal of sustainable means, preserved under any stage reforms and conditions of various forms of ideologically - artistic consciousness is done. Species characteristics of various dances are given and the synthetic nature of their figurative beginning is shown.

From the philosophical point of view, it is possible to study dance as an image and sign system, allowing you to take a fuller and deeper look at the specifics of dance means in terms of their semantic content. It is possible to determine the informative possibilities of a still image in the context of transmitting information about the statics and dynamics of the character and other components of dance and to make a description of the specificity of artistic imagery in choreographic art. "The study of dance as an image and sign system allows a fuller and deeper look at the specifics of dance language in terms of its semantic content. [11, p. 87]

Philosophical reflection on dance can follow the path of physiological study of its possibilities. The motional aspect of study includes its dynamics, because it potentially allows different muscle tension, possible balance points, any combination of movements, it represents the internally organized movements of the human body in space and time. Here it is interesting to reveal the processes of sensemaking in choreography, caused by artistic thinking and reflexive experience, as well as the processes of formmaking, connected with embodiment (the choice of expressive means and ways of their addition into speech units) and expression (character of performance) of the meaning of plastic language. [6]

You can follow the path of analyzing the morphological structure of the artistic language of dance and consider the basic methodological approaches for studying the artistic language of dance. "Dance language as the basis of choreography gives birth to its own meanings that have no verbal correlation, but it embodies intellectual content, ideological concepts at least as much as any other wordless arts". [2, p.11] It helps to show the essence of the academic system of dance language, in which any element of speech acquired semantic content only under the condition of its clear compositional organization, to give a substantiation of choreographic composition, the more distinctly it is built, the more clearly graphic and expressive elements of dance vocabulary are distributed in it.

Within the framework of the program study, dance can also be considered in the spiritual aspect, as the forms created in dance have certain characteristics that reflect different philosophical truths. One can examine the motional (sensual) aspect of dance. "A dancer does not think that his movements are correct, partially correct, incorrect. The dancer feels his movements."[22, p.56] In dance there is a simultaneous combination of psychological states in constant dynamics.

The psychological aspect of consideration of dance is also possible, as it reflects the personal characteristics of performers and choreographers, artists and composers, their philosophical vision and interpretation in each choreographic decision. It also includes the character of interpersonal communication among themselves, as well as their attitude towards themselves and their place in the creative process.

Finally, the program includes topics related to the anthropological ontology of dance. Here the analysis of philosophical, cultural and art criticism literature concerning the emergence and existence of dance at different stages of human culture is carried out. The philosophy of dance is revealed in the genesis of historical sensemaking. 
The choice of various philosophical aspects of the consideration of dance, touching upon issues of its general characteristics, evolution, personalities and choreographic works for discussion, is conducted in the form of lectures, practical exercises and forms of independent work.

\section{COMPETENT ASPECTS OF THE PROGRAM}

As a result of mastering the "Philosophy of Dance" discipline a master student is supposed to:

- $\quad$ know: the subject of dance philosophy, the basic principles, laws, categories, as well as their content and interrelationships, the basic laws of choreographic art functioning, the role of dance philosophy in forming value orientations in professional activity, the basic stages of history of development of philosophical views on the art of dance.

- be able to: orientate yourself in the system of philosophical knowledge as a holistic view of the foundations of the universe and the prospects of nature, society and thought, to understand the characteristic features of the current state of art philosophy, to apply the methods and criteria of philosophy of choreographic art in professional activity.

- $\quad$ to possess: skills of philosophic analysis of choreographic works, determination of general tendencies in development of art of dance, skills of evaluation of choreographic works using anthropological, ethical and aesthetic criteria, culture of thinking, ability to perceive, analyze, generalize aesthetic image in dance.

\section{CONCLUSION}

As we see, the knowledge of the fundamental characteristics of dance is directly connected with the interpretation of choreographic art as a philosophical model of its comprehension. The value lies in gaining experience, realizing your idea and thought in dance. Thus, dance can be considered not only as a means of emotional experience, but also as a means of self-knowledge, which in turn leads to effective self-expression and adequate construction of the process of social communication. This is what explains, in our opinion, the enormous importance of dance as a cultural phenomenon. The author sees the practical significance of the program itself in the possibility of including its provisions and the results of training in the historical and theoretical concept of choreographic culture. Themes and materials can be used not only in lecture courses, but also in the development of teaching aids and in the methods of choreographic training. Theoretical importance of the work lies in the multifaceted research of the language of choreographic art within the framework of the master's program, in which dance acts as a means of cognition, artistic philosophical communication, as well as a unique mechanism for obtaining research results in defense of master's qualification works in the field of choreographic art.

\section{REFERENCES}

1. Arnold P. Somaesthetics, Education, and the Art of Dance. - The Journal of Aesthetic Education Vol. 39, No. 1 (Spring, 2005), pp. 48-64

2. Atitanova N. V. Dance as a Semantic Universal: From the Expressive Movement to the "Movement" of Meanings: autoref. dis. - Saransk: 2000. - 18 p.

3. Blasis K. Dancing in General. Ballet Celebrities and National Dances. Saint Petersburg: LAN, planet of Music, 2008-352P.

4. Blok L. D. Classic Dance. History and the Present. - Moscow: Iskusstvo, 1987 - 556 P.

5. Camp. J. Philosophy of Dance. Dance Chronicle, 199619 (3): 347-357.

6. Carroll N. and. Seeley W. Kinesthetic Understanding and Appreciation in Dance - The Journal of Aesthetics and Art Criticism, Vol. 71, No. 2 (SPRING 2013), pp. 177-186

7. Dadianova T. V. Plasticity as a Physiognomic Characteristic of Art and the Category of Artistic Creativity. Yaroslavl, 1993 - p. 130

8. Davies D. Dancing Around the Issues: Prospects for an Empirically Grounded Philosophy of Dance. The Journal of Aesthetics and Art Criticism, Vol. 71, No. 2 (SPRING 2013), pp. 195-202

9. Filatov S. V. From the Figurative Word - to the Expressive Movement. M: Master,1993 - 128.

10. Gerasimova I. A. Philosophical Understanding of Dance // Questions of Philosophy. 1998. No. 4. P. 50-63 
11. Gevlenko Yu. a. Semiotic Analysis of Dance. - Bulletin of Tomsk State University. 2009, no. 320. pp. 87-89

12. The Philosophical Aesthetics of Dance: Identity, Performance, and Understanding by Graham McFee. 2011. Binsted, Hampshire: Dance Books Ltd. xvii + 342 pp

13. Kagan M. S. Morphology of Art. L.: Art, 1972 - 40 p.

14. Kagan M. S. Philosophy of Culture. SPb.: Petropolis, 1996 - 416 P.

15. Kondratenko Yu..A. The Language of Stage Dance: Types Specificity and Morphology. - Saransk: Publishing house of the Mordovian University, 2009-136 p.

16. Levinson A. Ya. Old and New Ballet. Saint Petersburg: LAN; Planet of Music, 2008. - 560 p.

17. Lugovaya E. K. Philosophy of Dance. Saint Petersburg: publishing house of St. Petersburg. UNTA, 2008-128 p.

18. Malkina-Pyh I. G. Body Therapy. M: Eksmo, 2005 - p. 960

19. Osintseva N.V. Philosophy of the Dance: When the Dance is More than Art.-The Social Sciences (Pakistan). 2016. Vol. 11. No. 29. P. 7036-7039.

20. Peters G. Improvising Improvisation: from out of Philosophy, Music, Dance, and Literature, University of Chicago Press, $2017-288$ p.

21. Redfern B. Philosophical Aaesthetics and the Study of Dance as an Academic Discipline. Research in Dance Education, 2007. pp. 187-201

22. Seiffert D. Pedagogy and Psychology of Dance. Notes of the Choreographer: a textbook / TRANS. from the German V. Stackenberg. Saint Petersburg: LAN, Planet of Music, 2012. 128 p.

23. Uralskaya V. I. The Nature of Dance - Moscow: Sov. Russia, 1981 - 112.

24. Valukin E. P. Problems of Heritage in Choreographic Art, Moscow: GITIS, 1992-169 p.

25. Wichurana L. K. The Language of Dance: Philosophical Analysis: abstract dis. - Ufa: Bashkir state University. UN-t, 2009. - $20 \mathrm{p}$.

26. Zorn A. Ya. The Grammar of Dance Art and Choreography. - Moscow: LAN, Planet of Music, 2011. - $544 \mathrm{p}$. 